\title{
RESPONSE OF TALL BUILDING SUBJECTED TO WIND LOADS UNDER INTERFERENCE CONDITION
}

\author{
Bharat S. Chauhan \\ Assistant Professor, Department of Civil Engineering, SATI Vidisha, Vidisha, India \\ Ashok K. Ahuja \\ Professor, Department of Civil Engineering, IIT Jammu, Jammu, India
}

\begin{abstract}
The research work presented in this paper investigates the effect of interference on different components of a tall building (principal building) having rectangular crosssectional shape due to the alteration of wind loads caused by the presence of another interfering building located close to the principal building. The two building models are arranged in such a manner so as to form a L-Shape in plan. The effect on the response of different components of the principal building is studied with the variation in height of the interfering buildings with respect to the principal building. Results are reported in the form of $X-Y$ plots. It seen that the response of the principal building components got significantly increased with respect to across wind displacement, twisting moment and bending moment caused by across-wind force.
\end{abstract}

Keywords: Height Variation, Interference Effect, L-Shape, Response Study, Tall Building.

Cite this Article: Bharat S. Chauhan and Ashok K. Ahuja, Response of Tall Building Subjected to Wind Loads Under Interference Condition. International Journal of Civil Engineering and Technology, 11(2), 2020, 156-163.

https://iaeme.com/Home/issue/IJCIET?Volume=11\&Issue=2

\section{INTRODUCTION}

With the growing demand of tall buildings in metropolitan cities due to population concentration, studies to understand effects of wind on these tall buildings have started to become inevitable. Information available in various codes of practice on wind loads ([1], [2], [3], [4]) provide guidance mostly limited to isolated cases with little preliminary information about interference cases.

Several research studies have been carried to understand the effect of wind on tall buildings due to the presence of other interfering buildings. To emphasize the importance of interference studies [5] gathered and analyzed the experimental data available on interference studies and concluded that the wind loads on the principal building are greatly affected if the interfering building is closely located. Numerous experimental studies related to interference 
have been carried out in the past ([6], [7], [8], [9], [10], [11], [12], [13], [14]). It has been shown these studies that the wind loads on tall buildings are greatly affected in the presence of closely located interfering buildings. Some studies related to the response are also available, [15] studied the response of building by conducting experiment on a model of tall building under interference condition with interfering building being located upwind but offset to one side, due to the presence of wake from upwind models the lateral displacements were noted to get enhanced. [16] explored the interference excitation on a tall building having square cross-section due to the presence of neighboring tall buildings. [17] presented results for longitudinal, lateral and torsional response of a square plan shape building model at different angles of wind incidence. [18] explored cross-wind vibration generated in super high-rise buildings having square, triangular, circular and Y-shape cross-sections due to vortex shedding under strong winds. [19] presented the response of aero-elastic model of rectangular cross-section tall building tested in boundary layer wind tunnel in the presence of rigid interfering building model placed upstream and downstream of the aero-elastic principal building model, due to the presence of interfering building, the mean response of the principal building reduced due to shielding while the dynamic response enhanced. [20] presented a laser positioning technique useful for direct measurement of tip displacement of tall building models under simulated wind environment. [21], [7], [22], and [23] carried out analytical response by the application of experimentally obtained wind loads on prototype tall buildings, however none of the mentioned studies address the response study of rectangular plan building under interference condition.

Therefore, an attempt has been made here to study the effect of interference on members of the prototype building due to the alteration of wind loads under the presence of closely located interfering building. Principal building considered here is rectangular in plan, interfering building having a similar plan shape is arranged in such a manner so as to form a L-shape pattern in plan (Fig. 1). Wind tunnel studies have been carried out to study the effect of interference on wind pressure distribution. The height of interfering building is varied to understand its effect on wind pressure distribution. The results obtained from wind tunnel studies are implemented into a STAAD.Pro model of the prototype building and the effect of wind interference on different building members is studied. Results of the response measurement are presented in the form of X-Y plots showing the variation of forces, moments and displacements.

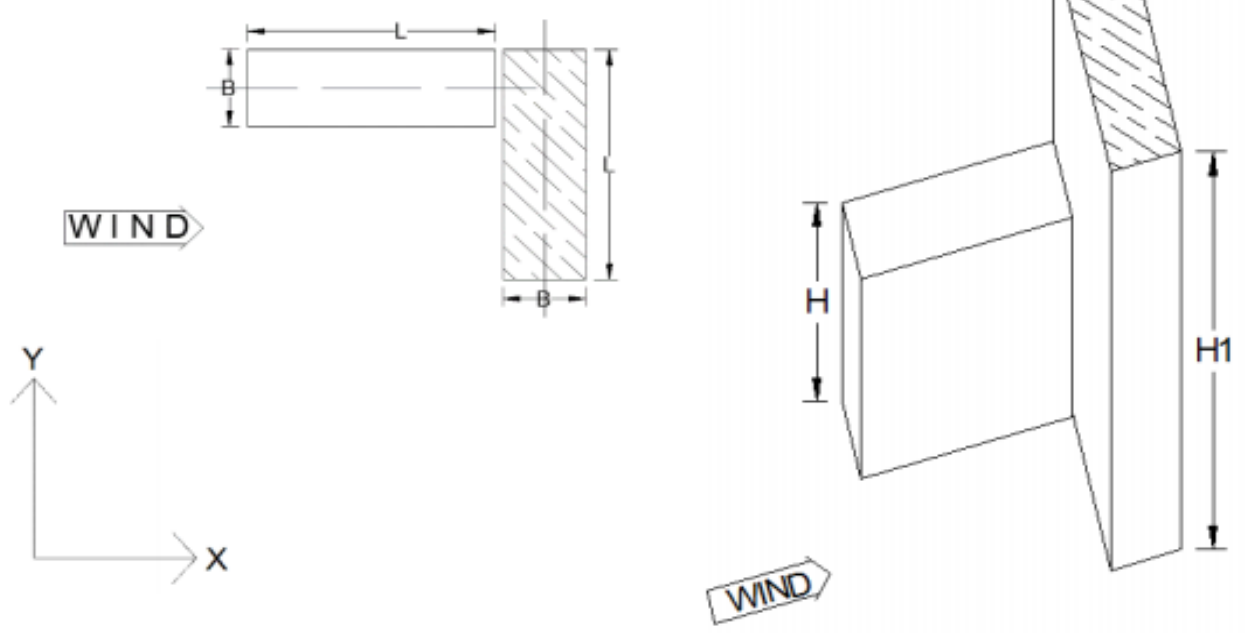

Figure 1. Plan and isometric view of the arrangement. (All dimensions are in $\mathrm{mm}$ ) $[\mathrm{H} / \mathrm{H} 1=0.0,0.2$, $0.6,1.0 ; \mathrm{L} / \mathrm{B}=3.0]$ 


\section{RESEARCH METHODOLOGY}

\subsection{Experimental Modelling}

Prototype considered for the principal tall building in the given study is of rectangular shape in plan having plan dimensions of $60 \mathrm{~m} \mathrm{x} 20 \mathrm{~m}$ (i.e. $1200 \mathrm{~m}^{2}$ area in plan) and having height of $100 \mathrm{~m}$ which correspond to width to length ratio of $1: 3$ and width to height ratio of 1:5. Similarly, the prototype considered for the interfering tall building in the study are also of rectangular shape in plan having plan dimensions of $60 \mathrm{~m} \times 20 \mathrm{~m}$ (i.e. $1200 \mathrm{~m}^{2}$ area in plan) and height as $100 \mathrm{~m}, 60 \mathrm{~m}$ and $20 \mathrm{~m}$. Pressure measurements are conducted under the mean wind velocity profile corresponding to power law exponent of 0.3 , by using rigid models of rectangular shape tall buildings for both principal and interfering buildings made of Perspex sheet and Plywood respectively to a scale of 1:200. Figure 2 shows the photographs for different cases considered for wind tunnel experimental study.

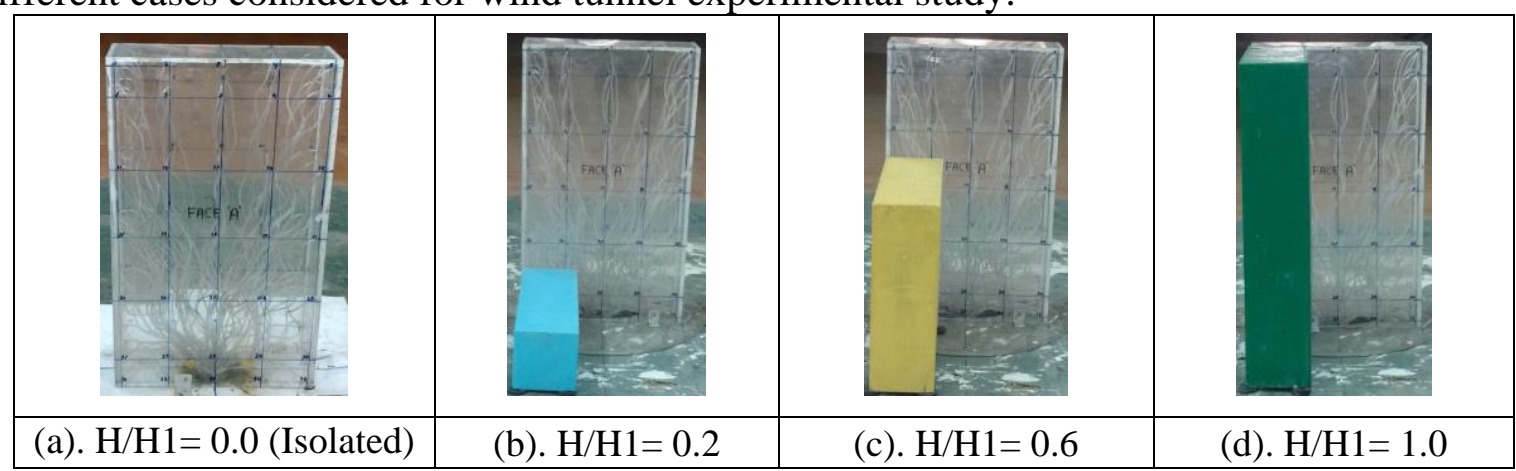

Figure 2. Photographs of different cases considered for pressure measurement.

\subsection{STAAD Pro Modelling}

The prototype building is modelled in STAAD Pro with the assumptions as stated in Table 1 . The value of mean pressure coefficient $\left(\bar{C}_{P}\right)$ is obtained at the locations of different beam column junctions on different faces of the principal building from the contours obtained by wind tunnel experimentation. Using the value of mean pressure coefficients and the tributary area the nodal forces on the beam column junctions is obtained. These forces are applied on different beam column junctions of the principal building model as wind loads.

Table 1. Assumptions used in STAAD Pro modelling.

\begin{tabular}{|c|l|l|}
\hline Sr. No. & \multicolumn{1}{|c|}{ Particular } & \multicolumn{1}{|c|}{ Numerical Value } \\
\hline 1. & Dimensions of the prototype building $(\mathrm{L} \times \mathrm{B} \times \mathrm{H})$ & $60 \mathrm{~m} \times 20 \mathrm{~m} \times 100 \mathrm{~m}$ \\
\hline 2. & Bay to Bay distance along length and along breadth & $5 \mathrm{~m}$ \\
\hline 3. & Grade of Concrete / Grade of Steel & $\mathrm{M} 25 / \mathrm{Fe} 500$ \\
\hline 4. & Load due to finish & $1 \mathrm{kN} / \mathrm{m}^{2}$ \\
\hline 5. & Live load -All floors except roof/roof & $4 \mathrm{kN} / \mathrm{m}^{2} / 2 \mathrm{kN} / \mathrm{m}^{2}$ \\
\hline 6. & Thickness of partition walls and parapet & $110 \mathrm{~mm}$ \\
\hline 7. & Density of brickwork & $20 \mathrm{kN} / \mathrm{m}^{3}$ \\
\hline 8. & Storey height - first / others & $4.3 \mathrm{~m} / 3.3 \mathrm{~m}$ \\
\hline
\end{tabular}

Figure 3 shows the front elevation, side elevation and isometric view of the prototype building giving the distribution of beams and columns. Figure 4 shows the STAAD Pro model displaying the wind loads for $\mathrm{H} / \mathrm{H} 1=0.0$ (or isolated case), in this case since the side faces will experience equal wind pressure due to symmetry and will cancel each other out hence no 
wind loads have been applied on them, however for interference cases wind loads are applied on all vertical faces of the principal building.
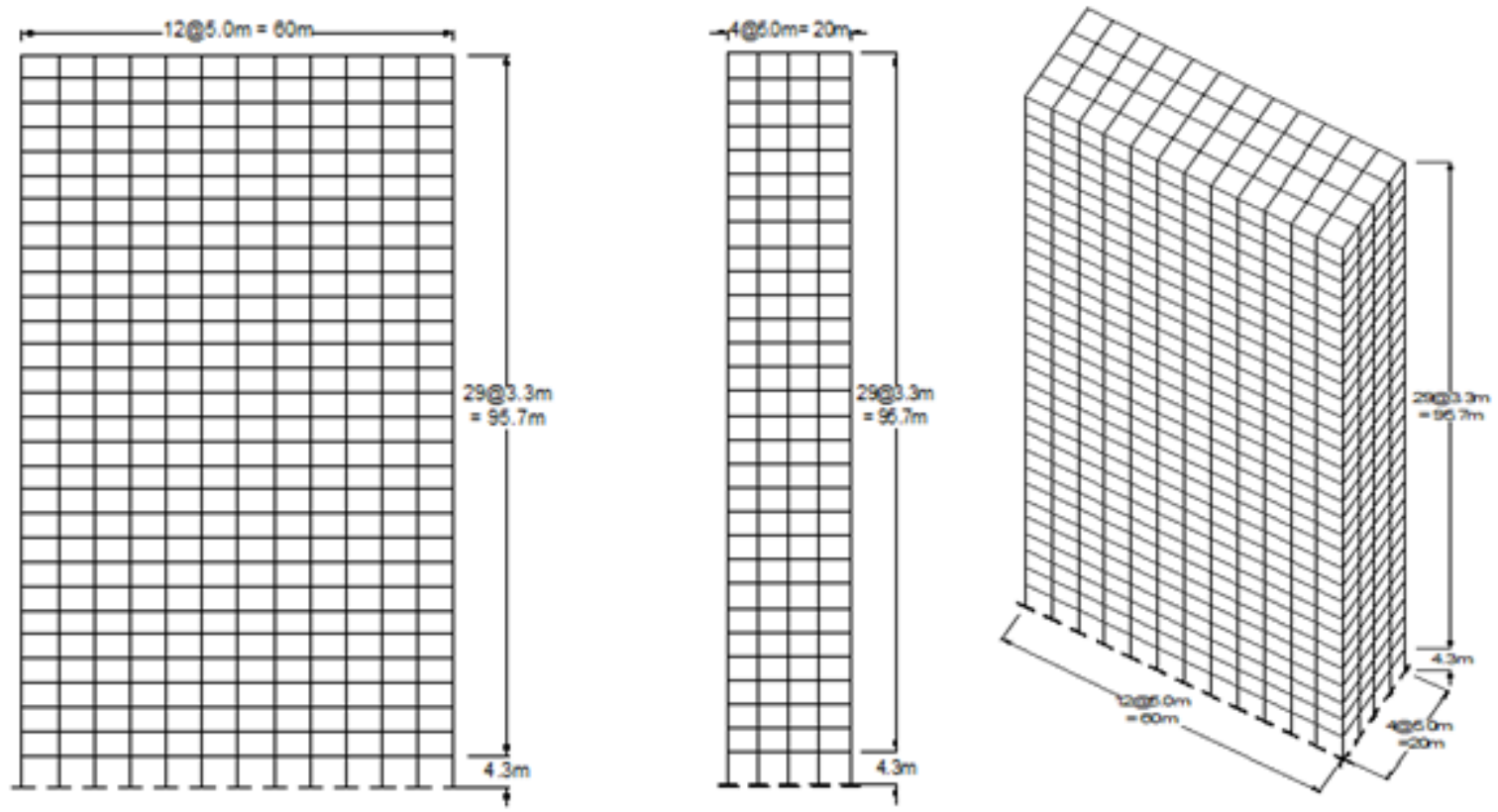

Figure 3. Front elevation, side elevation and isometric view of the prototype building.
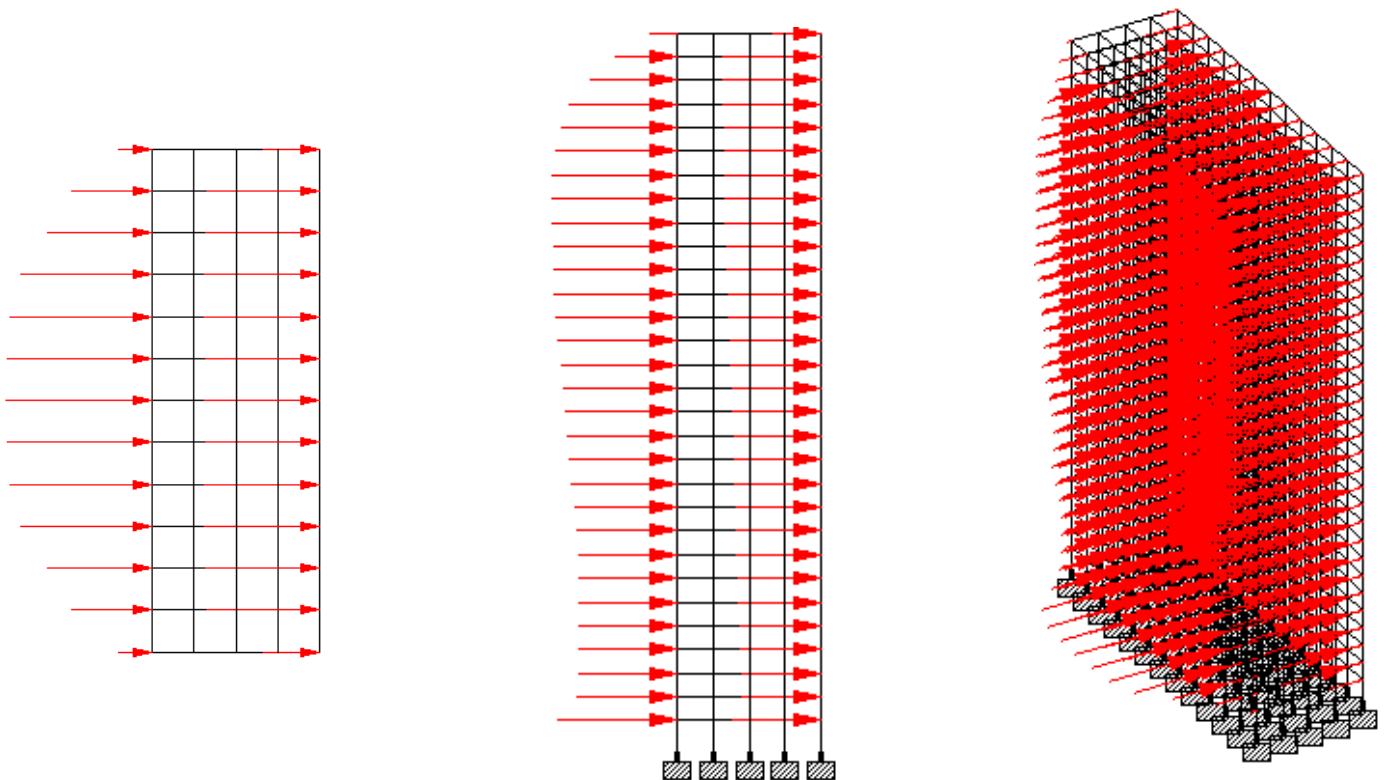

Figure 4. Plan view, side elevation and isometric view of the STAAD Pro model with wind loads for $\mathrm{H} / \mathrm{H} 1=0.0$ (or isolated case)

Indian Standard code IS 456: 2000 is used for the design of different structural members, the sizes obtained are shown in Table 2 along with other design parameters. 
Table 2. Design Parameters.

\begin{tabular}{|c|c|c|c|}
\hline Sr. No. & \multicolumn{2}{|c|}{ Particular } & Numerical Value \\
\hline 1. & \multicolumn{2}{|l|}{ Code of practice } & IS 456: 2000 \\
\hline 2. & \multicolumn{2}{|l|}{ Load Combination 1} & $1.5(\mathrm{DL}+\mathrm{LL})$ \\
\hline 3. & \multicolumn{2}{|l|}{ Load Combination 2} & $1.2(\mathrm{DL}+\mathrm{LL}+\mathrm{WL})$ \\
\hline 4. & \multicolumn{2}{|c|}{ Size of reinforced concrete beams } & $300 \mathrm{~mm} \times 600 \mathrm{~mm}$ \\
\hline 5. & \multicolumn{2}{|c|}{ Thickness of reinforced concrete slabs } & $150 \mathrm{~mm}$ \\
\hline \multirow{5}{*}{6.} & \multirow{5}{*}{$\begin{array}{l}\text { Size of reinforced concrete } \\
\text { columns }\end{array}$} & $1^{\text {st }}$ to $6^{\text {th }}$ storey & $900 \mathrm{~mm} \times 900 \mathrm{~mm}$ \\
\hline & & $7^{\text {th }}$ to $12^{\text {th }}$ storey & $750 \mathrm{~mm} \times 750 \mathrm{~mm}$ \\
\hline & & $13^{\text {th }}$ to $18^{\text {th }}$ storey & $600 \mathrm{~mm} \times 600 \mathrm{~mm}$ \\
\hline & & $19^{\text {th }}$ to $24^{\text {th }}$ storey & $450 \mathrm{~mm} \times 450 \mathrm{~mm}$ \\
\hline & & $25^{\text {th }}$ to $30^{\text {th }}$ storey & $300 \mathrm{~mm} \times 300 \mathrm{~mm}$ \\
\hline
\end{tabular}

DL - Dead Load, LL - Live Load, WL - Wind Load.

\section{RESULTS AND DISCUSSION}

Response results are reported for two columns: Column A and Column B shown in Figure 5. The obtained response results are presented in the form of X-Y plots for Column A and Column B in Figures 6 and 7 respectively. For both Column A and B, results are shown for axial force, twisting moment about vertical axis $(\mathrm{Mz})$ and bending moments about two crosssectional axis ( $\mathrm{M}_{\mathrm{X}}$ and $\mathrm{MY}$ ) of the building. For Column A displacements in along wind and across wind directions is also reported. It can be noted from Figures 6 and 7, that peak value of axial force for both Column A and B reduce as height of interfering building increases (or $\mathrm{H} / \mathrm{H} 1$ increases) due to shielding effect. The twisting moment $\mathrm{Mz}$ peak value is however noted to increase with the increase in interfering building height for both columns. Peak value of bending moment $\mathrm{Mx}$ caused by the across wind force is noted to be slightly higher for Column B for all cases in comparison to that for Column A, with highest magnitude being noted for $\mathrm{H} / \mathrm{H} 1=1.0$ at the base.
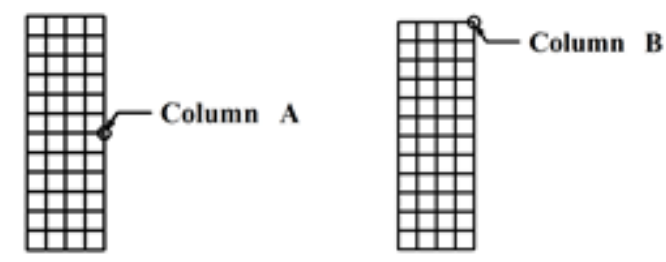

Figure 5. Plan view of prototype building displaying position of Columns A and B Figure 6. Response results for Column A

Bending moment My caused by the along wind force is noted to be higher for Column A for $\mathrm{H} / \mathrm{H} 1=1.0$ at the base in comparison to that for Column B due to higher shielding effect, for isolated condition almost similar value is obtained for both the columns but with the increase in height of interfering building the magnitude of $\mathrm{MY}$ is noted to decrease at higher rate for Column B. Observing the figures for along wind and across wind displacements for Column A, it can be noted that with the increase in height of interfering building peak value of along wind displacement decreases while the peak value of across wind displacement increases tremendously. 

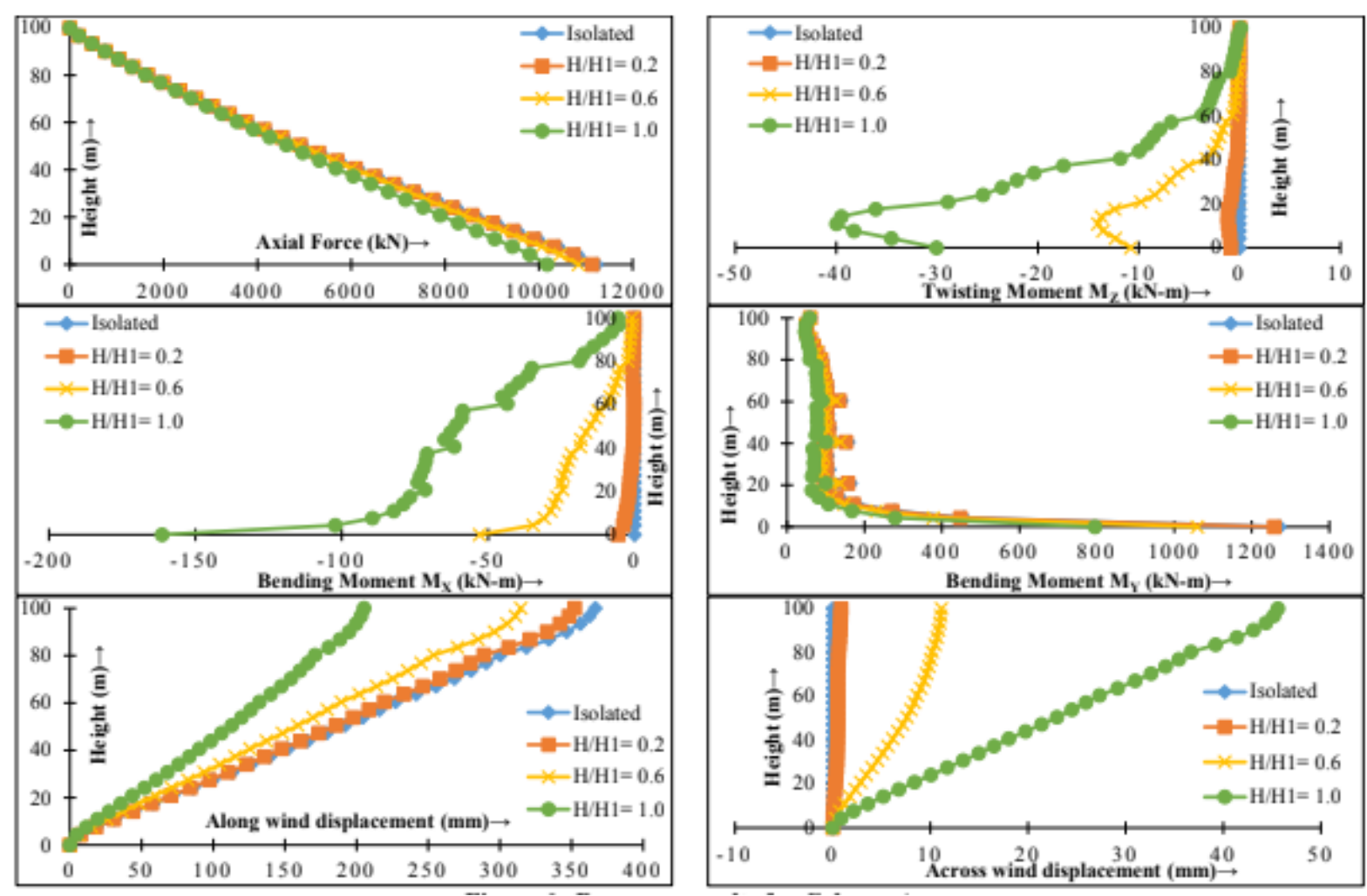

Figure 6 Response results for Column A
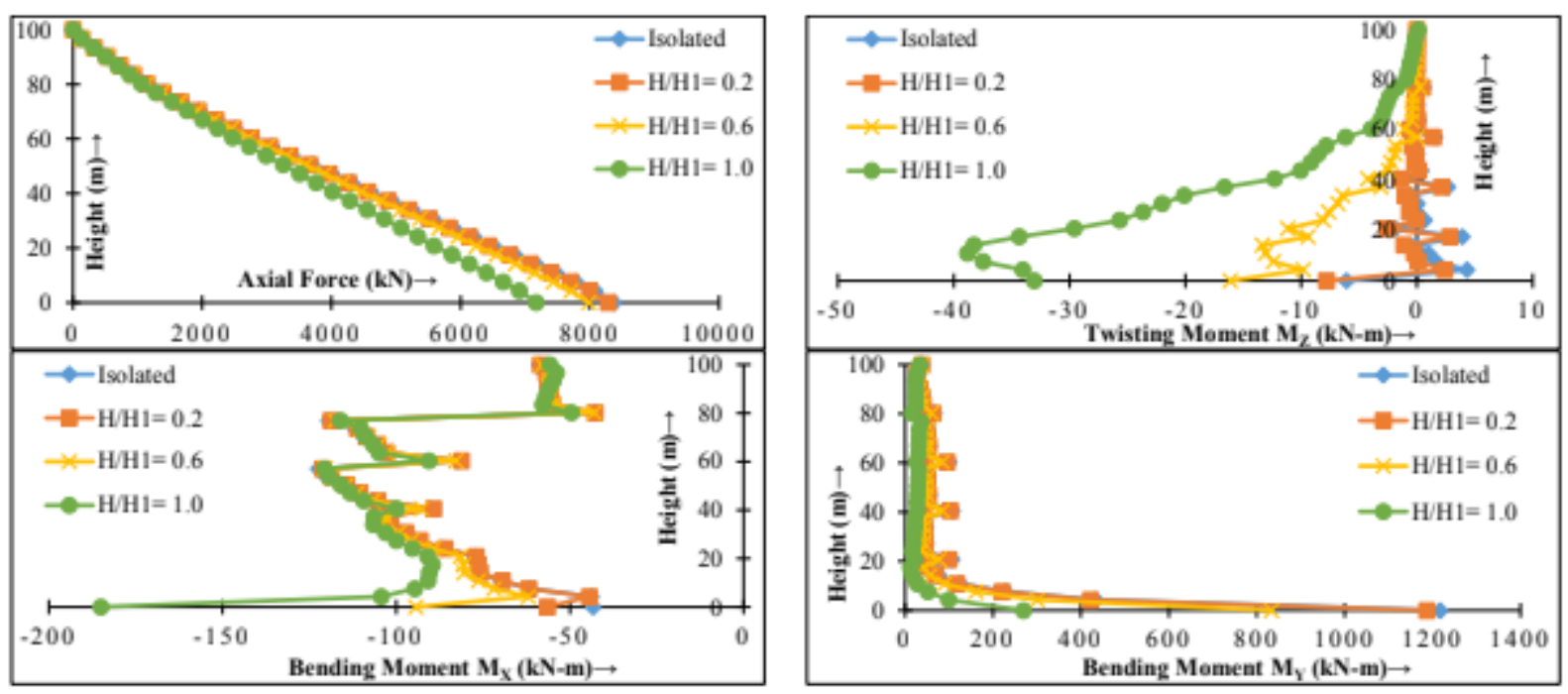

Figure 7 Response results for Column B

\section{CONCLUSIONS}

- Peak value of axial force, displacement in along wind direction and bending moment caused by the along wind force are noted to reduce for both Columns, with increase in height of interfering building (or $\mathrm{H} / \mathrm{H} 1$ increase) due to shielding effect.

- Peak value of twisting moment, displacement in across wind direction and bending moment caused by across wind force are noted to enhance significantly for both Columns, with increase in height of interfering building. 


\section{ACKNOWLEDGEMENT}

The work reported in the manuscript was funded by research grants made available by the first author's host institute (Indian Institute of Technology Roorkee, Roorkee, India) for pursuing doctoral degree.

\section{REFERENCES}

[1] AS/NZS: 1170.2-2002, Australian/New Zealand Standard: Structural Design Actions Part2: Wind Actions, 2002.

[2] ASCE: 7-02-2002, American Society of Civil Engineers: Minimum Design Loads for Buildings and Other Structures, 2002.

[3] EN: 1991-1-4-2005, Euro Code 1: Actions on Structures - Wind Actions, 2005.

[4] IS: 875 (Part-3) 2015, Code of Practice for Design Loads (other than Earthquake Loads), for Building and Structures - Wind Loads, 2015.

[5] A.C. Khanduri, T. Stathopoulos, and C. Bédard, Wind induced interference effects on buildings - a review of the state-of-the-art, Engineering Structures, 20, 1998, 617-630.

[6] Z.N. Xie, and M. Gu, Mean interference effects among tall buildings, Engineering Structures, 26, 2004, 1173-1183.

[7] J. Amin, Effects of plan shape on wind induced response of tall buildings, Ph.D. Thesis, Department of Civil Engineering, Indian Institute of Technology Roorkee, India, 2008.

[8] J.G. Zhao, and K.M. Lam, Interference effects in a group of tall buildings closely arranged in an L- or T-shaped pattern, Wind and Structures, 11(1), 2008, 1-18.

[9] W. Kim, Y. Tamura, and A. Yoshida, Interference effects on local peak pressures between two buildings, Journal of Wind Engineering and Industrial Aerodynamics, 99, 2011, 584600 .

[10] T. Kushal, Effect of plan shapes on the response of tall buildings under wind loads, M.Tech. Thesis, Department of Civil Engineering, Indian Institute of Technology Roorkee, India, 2013.

[11] S.C. Pandey, Influence of proximity on the response of tall buildings under wind loads, M.Tech. Thesis, Department of Civil Engineering, Indian Institute of Technology Roorkee, India, 2013.

[12] T.G. Mara, B.K. Terry, T.C.E. Ho, and N. Isyumov, Aerodynamic and peak response interference factors for an upstream square building of identical height, Journal of Wind Engineering and Industrial Aerodynamics, 133, 2014, 200-210.

[13] B. Yan, and Q.S. Li, Wind tunnel study of interference effects between twin super-tall buildings with aerodynamic modifications, Journal of Wind Engineering and Industrial Aerodynamics, 156, 2016, 129-145.

[14] B.S. Chauhan, and A.K. Ahuja, Effect of height variation of closely located interfering buildings on wind loads on tall buildings, International Journal of Earth Sciences and Engineering, 10, 2017, 378-382.

[15] D.M. Sykes, Interference effects on the response of a tall building model, Journal of Wind Engineering and Industrial Aerodynamics, 11 (1), 1983, 365-80.

[16] P.A. Bailey, and K.C.S. Kwok, Interference excitation of twin tall buildings, Journal of Wind Engineering and Industrial Aerodynamics, 21, 1985, 323-38.

[17] T. Balendra, and G.K. Nathan, Longitudinal, lateral and torsional oscillations of a square section tower model in an atmospheric boundary layer, Engineering Structures, 9 (4), 1987, 218-24. 
[18] H. Hayashida, and Y. Iwasa, Aerodynamic shape effects of tall building for vortex induced vibration, Journal of Wind Engineering and Industrial Aerodynamics, 33(1), 1990, 237-42.

[19] Y. Mahmood, K. Kumar, P. Krishna, and P.K. Pande, Aerodynamic interference in tall rectangular buildings, Journal of Wind Engineering and Industrial Aerodynamics, 41(1), 1992, 859-66.

[20] T. Balendra, M.P. Anwar, and K.L. Tey, Direct measurement of wind-induced displacement in tall building models using laser positioning technique, Journal of Wind Engineering and Industrial Aerodynamics, 93, 2005, 399-412.

[21] S.K. Dalui, Wind effects on tall buildings with peculiar shapes, Ph.D. Thesis, Department of Civil Engineering, Indian Institute of Technology Roorkee, India, 2008.

[22] P. Misra, Effect of location of shear walls on the response of tall buildings under wind loads, M.Tech. Thesis, Department of Civil Engineering, Indian Institute of Technology Roorkee, India, 2017.

[23] S. Magotra, Effect of corner configuration on response of tall buildings under wind loads, M.Tech. Thesis, Department of Civil Engineering, Indian Institute of Technology Roorkee, India, 2017. 